\title{
USING OF ROBOTS-MANIPULATORS IN LABORATORY WORKS IN HIGHER EDUCATION INSTITUTES
}

\author{
V. Yehorov ${ }^{1}$, D. Putnikov ${ }^{2}$ \\ ${ }^{1,2}$ Odessa national Academy of Food Technology, Odessa \\ ORCID: ${ }^{1} 0000-0003-4699-834 \mathrm{X},{ }^{2} 0000-0003-2577-8858$ \\ E-mail: ${ }^{1}$ yegorov-victor@mail.ru, ${ }^{2}$ dn.p@mail.ru
}

Copyright (C 2014 by author and the journal "Automation technological and business - processes". This work is licensed under the Creative Commons Attribution International License (CC BY). http://creativecommons.org/licenses/by/4.0/

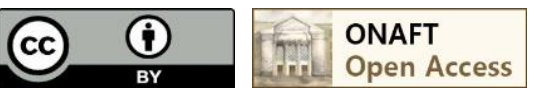

Abstract: Studying of technical disciplines in higher education institution as a rule consists of 2 parts - theories and practice. Practice, is a type of educational process which allows to realize theoretical knowledge to the applied sphere. In particular it allows to provide an object visually, creating its image and visually adequate perception. This work is devoted to development of laboratory base of technical college with use of robots manipulators on occupations. Its relevance is shown. The overview of modern stands is provided in different higher education institutions, the analysis of their benefits and shortcomings is this. The task of creation of the robot manipulator for sorting of objects of color is set. The robot model including an automatic management system it is developed. The sensor of color, the regulator and the executive mechanism allowing to move objects to the corresponding reservoirs is its part. Possibilities of further development of a question, in particular, creations of physical model for use are given in laboratory works.

Key words: Robot-manipulator, education process, laboratory working, controlled object, MT-11, computer vision library, laboratory of mechatronics and robotics, pneumatic.

Integral part of process of training of the students learning technical disciplines is fixing of the material passed at lectures by carrying out laboratory works.

Modern requirements to statement of educational process provide that on laboratory researches work with the exercise machines imitating real installation, objects of a research, a condition of carrying out an experiment is carried out. Such exercise machines provide conditions and the measuring devices necessary for a real experiment. Work with exercise machines allows to receive skills in drawing up sketches, schemes of the organization of a laboratory experiment, to gain an evident impression about object of studying that is important at development by students of any subjects.

Students of electromechanical disciplines study the different installations intended for accomplishment of various tasks on production. One of types of such installations is the manipulator which is intended for movement of objects from one provision in another.

At the same time it is important, for the best development by students that the laboratory stand had some qualities:

- visualization of construction. It means that the student shall have an opportunity explicitly to study each node. For what it is desirable that mounting was made so that whenever possible each circuit element was available to a look;

- convenience of mounting of control diagrams. As a rule the job of the student on operation on the laboratory bench includes compilation of its control diagram, and it means that the maximum convenience to execution of this purpose shall be provided.

There have developed laboratory stands of robots manipulators for studying by students in some Higher education institutions.

For example, the Balakovo institute of the equipment, technology and management - Public Educational Institution of Higher Professional Training Saratovskogo Gosudarstvennogo branch of technical university has developed two laboratory stands of the manipulator on the basis of ARIESES devices which he has received according to the high school program free of charge [1].

One of them - the laboratory stand for development of the system of control of the Electronics SC TM-01 robot manipulator based on PLC developed at "Technology and Automation of Mechanical Engineering" department. Object of management in this laboratory stand is the "Electronics SC TM-01" robot manipulator belonging to the first class of robots manipulators for automatic or flexible production. This robot is intended for servicing of metal-cutting machines, namely: for 
loading and unloading of details like bodies of rotation with a diameter up to $150 \mathrm{~mm}, 150 \mathrm{~mm}$ high, and also in case of production of products of the electronic industry. Change of the executive mechanism of the robot allows to adapt the robot on accomplishment of various transactions. The laboratory stand (fig. 1) consists from: directly the robot manipulator (fig. 3) and the control unit (fig. 2)on the basis of ARIESES devices. The block of a control system is assembled in the metal case with the transparent forward door allowing to clearly demonstrate work of a control system and preventing contact of a student with open current carrying parts.

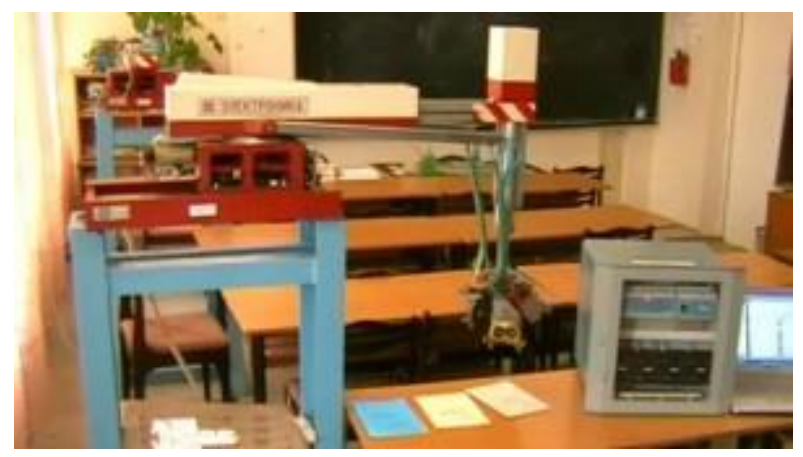

Fig. 1 - Laboratory stand

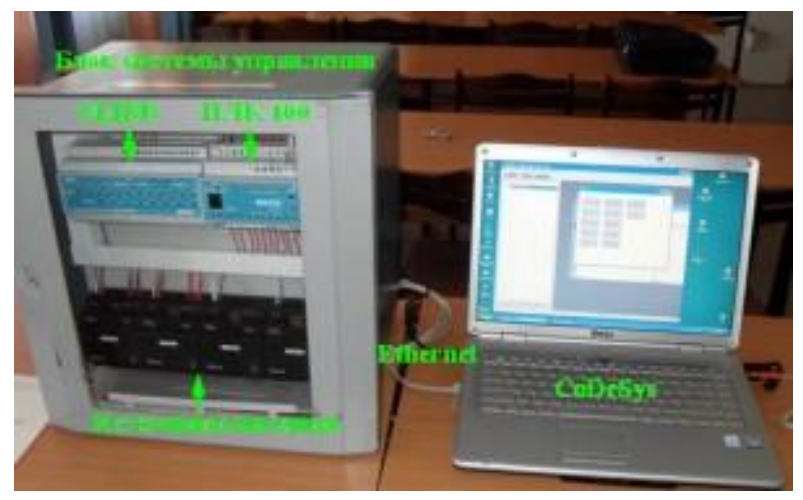

Fig. 2 - Appearance of the block of the robot control system by the manipulator "Electronics NC TM-01"

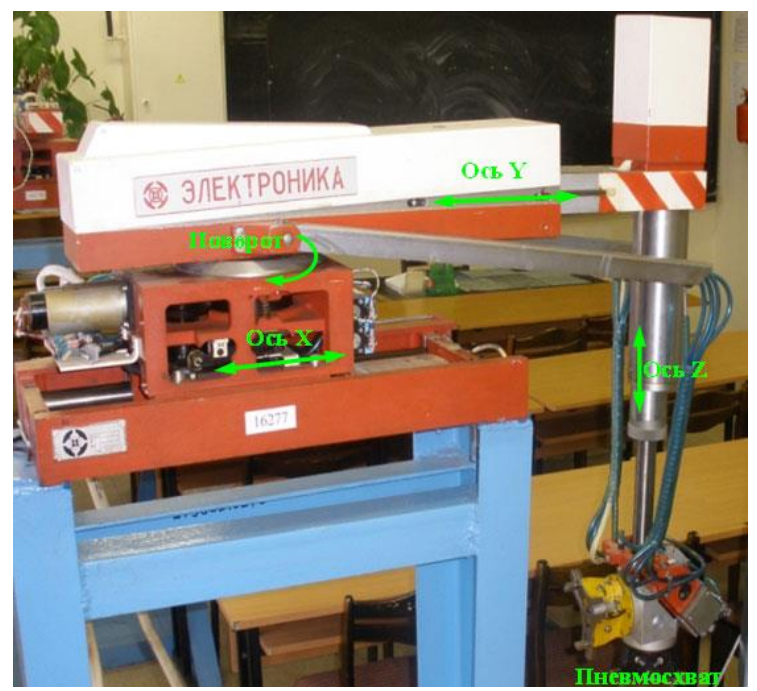

Fig. 3 - Appearance of the robot manipulator "Electronics NC TM-01"

The second one is the laboratory bench for development of the system of control of the pneumorobot manipulator MT11 on the basis of a PLC.

Controlled object in this laboratory stand is the robot manipulator MT-11belonging to the first class of robots manipulators for automatic or flexible production. This robot was developed for needs of domestic automotive industry (AvtoVAZ). Change of the executive mechanism of the robot allows to adapt the robot on accomplishment of various transactions. The management system is constructed based on the PLC100 ARIES programmable logical controller. Developed 
methodical material will be used when carrying out the practician on rates "Elements and devices of management systems", "Microprocessor management systems in mechanical engineering".

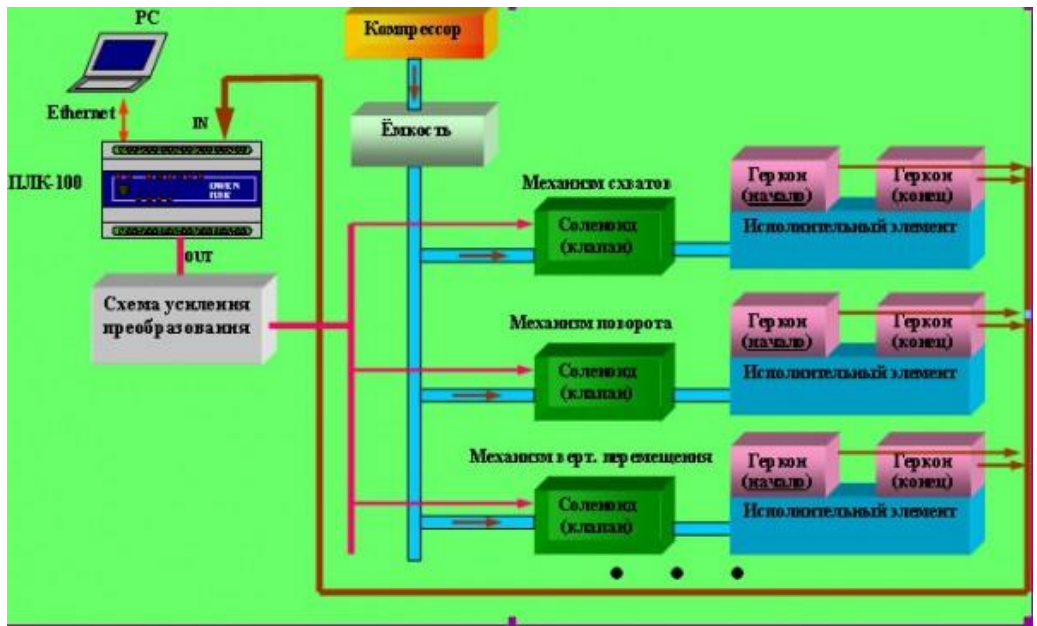

Fig. 4 - Functional diagram of the robot control system by the manipulator "Electronics NC TM-01"

One more successful stand is the stand, with the mounted robot manipulator, intended not only for carrying out laboratory works students during the laboratory researches on a subject matter "Technical means of automation and management", but also uses of development during research works on the subjects connected with computer sight and a visual servo control has been developed at the Perm national research polytechnical university at «Automation and Telemechanics» department [2].

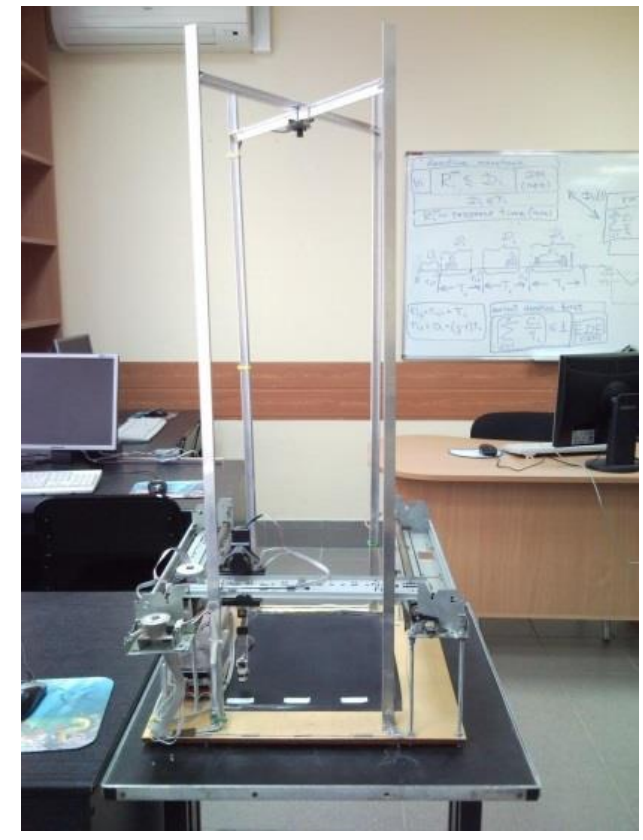

Fig. 5 - Robot-sorter (general view)

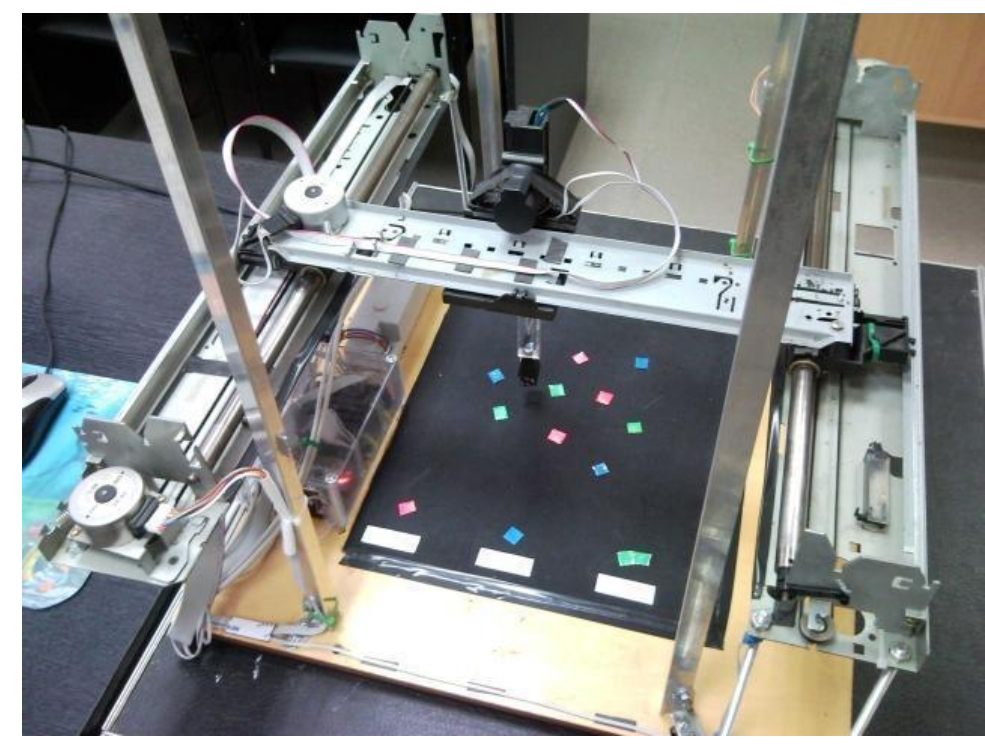

Fig. 6 - Robot-sorter (working area)

The robot sorter presents itself the manipulator system form with the magnetic capture moved on a vertical axis. The manipulator can freely move on the area of 30 by $40 \mathrm{~cm}$ by means of stepping motors, metal guides and the belt drive. By means of the pointing device, the robot can capture metal objects and move them to target areas, sorting them by external signs. Recognition of these signs is carried out by means of the camcorder located over a sort field.

The intellectual component of the robot is distributed between the microcontroller and the controlling computer, at the same time its main part is laid to the controlling computer to which, in particular, the video camera is connected. For obtaining the picture on the bench the webcam connected to the computer on USB is used.

As the devices responsible for moving the manipulator, it was decided to use stepper motors because of the ease of positioning with them. To reduce the cost of manufacturing the stand, four EM-142 and EM-141 stepper motors were used from old Epson LX1050 printers. 
In order for the robot-sorter to transfer parts from one place to another, it was necessary to implement the vertical movement of the manipulator. As a vertically moving part, the automotive door activator Saturn MS-2 was chosen. When developing a manipulator, an electromagnet is used as a gripping device. This seems to be the most suitable solution for this stand at the initial stage due to the ease of implementation.

All control schemes of power mechanisms were assembled on the same board with the necessary connectors and a radiator, forming a control unit for power mechanisms.

As the controlling controller, the Arduino family controller (Carduino Nano v4) was chosen. It has an open architecture, as well as a freely distributed development environment. For digital I / O, 14 contacts are used, six of which can be used to output PWM signals. There are also six analog inputs with an ADC of 10 bits.

The tasks those are put before the controller are, basically, tasks related to controlling actuators and interaction with sensors. All logical operations for moving the manipulator and image processing are carried out by the computer to which the controller is connected.

The robot-sorter performs search and sorting of objects by this or that criterion. For example, it can be just a search for objects of a certain color, or you can sort objects by their size.

The main block in the cycle of functioning looks, in general terms, as follows.

Using a web camera, a snapshot of the site with objects in the form of a bitmap image is created, which is stored in the RAM.

On the resulting image, the next object is searched.

Determines whether the object belongs to a particular category of objects according to a specified characteristic (for example, color, shape or size).

Moves the manipulator to the object. After moving the manipulator is located exactly above the object. The movement can be carried out either by calculating the required number of steps for the control motors, or by adjusting the position of the manipulator in the video image.

One can single out the following main ways of development and modification of the laboratory stand "Robot-sorter".

Implementation of more complex image recognition algorithms, in particular, using OpenCV's freely available computer vision library.

Connecting additional webcams, which will allow to determine the position of objects not only on the plane, but also in three-dimensional space. In particular, it will be possible to evaluate the height of objects, their true shape, and not just one of the projections of the object, as it is now.

Creating a more complex manipulator, for example, in the form of a "mechanical hand" of this or that complexity. Combined with additional webcams, this will allow you to explore and develop more complex and interesting methods and algorithms for visual servoing, where, in particular, webcams play the role of feedback sensors.

In the Odessa national academy of food technologies in laboratory of mechatronics and robotics the stand with the robot manipulator for sorting of objects of color consisting completely of pneumatic executive mechanisms has also been developed. The robot is intended for carrying out by students laboratory works on studying of operation of pneumatic executive mechanisms and to creation of control algorithms to them.

The robot consists of a platform 1 with holes (fig. 8 - a type of a platform on top) on which there is a plane 2 which can reciprocally move, and also from the camera 3 for reception of balls which is on midplane and moves reflexive rotationally. Construction as follows works: the ball 1, by gravity gets to the camera on top from situation $a$ and, to situation $\sigma$ where color of a ball by means of the sensor of color is defined. Then information goes to the controller which sends the controlling signals to pneumatic cylinders of 8 (fig. 7) and 9 (fig. 9), one of which is connected to the camera, and another - with midplane. As soon as the camera moves to the necessary line item and a ball, by gravity falls in a basket through a hole in the lower plane, cylinders 8 and 9 move mechanisms 2 and 3 to initial situation and the cycle is repeated.

Also, between the camera 3 and a neck 6 the latch 5 in case of which complete promotion on the controller the test signal that it is possible to begin movement, and in case of incomplete - a signal that it is impossible to begin movement arrives is set. It prevents breakage of the camera the objects restricting relocation of the camera. Movement of a latch is carried out by a pneumatic cylinder 4 [3].

Summary

Important part of training process of the students studying technical disciplines is fixing of the material passed at lectures by carrying out laboratory works. Modern requirements to statement of educational process provide, carrying out on laboratory researches of works with the exercise machines imitating real installation, objects of a research, a condition of carrying out an experiment. Work with exercise machines allows to gain an evident impression about object of studying that is important in case of development by students of any subjects. Within this work the pneumorobot manipulator which is consisting completely of pneumatic executive mechanisms and having such advantages as presentation of a design, convenience of installation of schemes of management, safety to students and protection against hit of external objects was developed. This development is intended to help students to expand idea of modern means of sorting. 

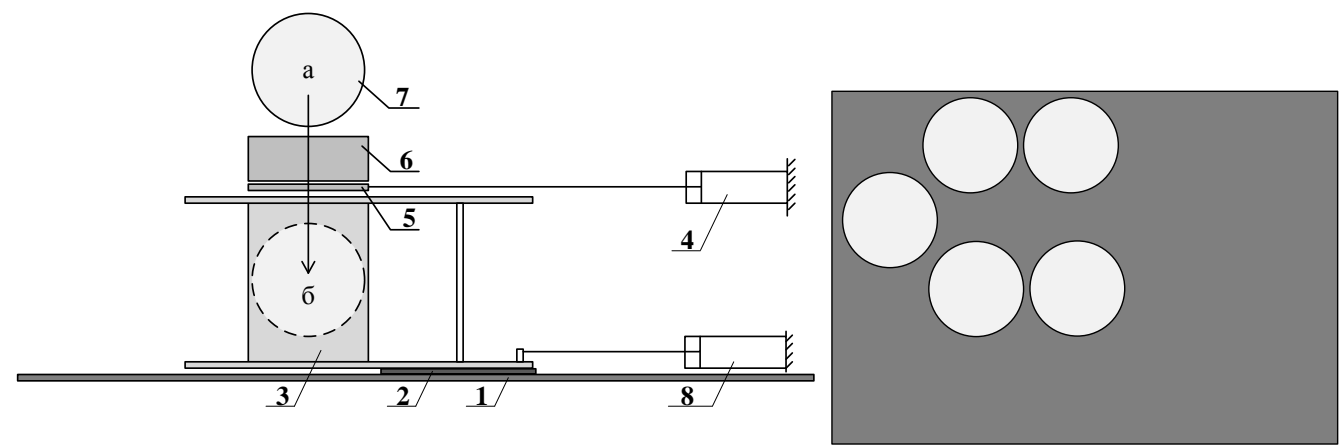

Fig. 7 - Type of Model in front

Fig. 8 - Type of a Platform from above

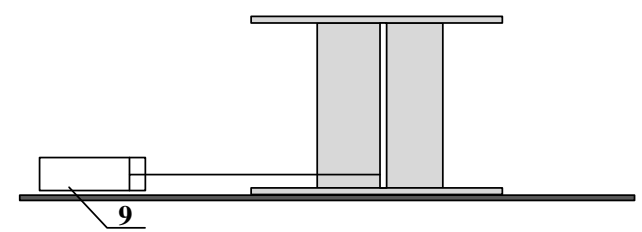

Fig. 9 - Type of Model at the left

\section{Reference}

[1] Owen. “Балаковский институт техники, технологии и управления - филиал ГОУ ВПО Саратовского Государственного технического университета," owen.ru. [Online]. Available: http://www.owen.ru/56504463. [Accessed: Oct. 31, 2016];

[2] Pstu.“Лабораторный стенд "Робот сортировщик", http://at.pstu.ru/view/Лабораторный_стенд:Робот-сортировщик. [Accessed: Oct. 31, 2016];

V. B. Yegorov, D. V. Putnikov, A. Yu. Latyshev, “Отчет о результатах конкурса, проведенного на базе НИЛ Мехатроники и робототехники и компании "Camozzi»," in Information technologies and automation: Proceedings for the 8-th annual scientific conference, 2015, Odessa, Ukraine, Oct. 15-16 2015, D. V. Putnikov, Eds.: Odessa: ONAFT, 2015. pp. 45-46.

\section{IMPROVED MODELS AND METHOD OF POWER CHANGE OF NPP UNIT WITH VVER-1000}

\section{T. Foshch ${ }^{1}$, S. Pelykh²}

${ }^{1,2}$ Odessa National Polytechnic University

ORCID: ${ }^{1}$ 0000-0001-8801-0382; ${ }^{2} 0000-0003-1608-8089$

E-mail: 1antariuz@gmail.com; ${ }^{2}$ pelykh@i.ua

Copyright (C) 2014 by author and the journal "Automation technological and business - processes". This work is licensed under the Creative Commons Attribution International License (CC BY). http://creativecommons.org/licenses/by/4.0/

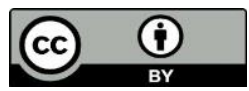

ONAFT

Open Access

Abstract: This study represents the improved mathematical and imitational allocated in space multi-zone model of VVER- 